\title{
Replacing Happiness with Meaning An Interview Structure for Formulating Life's Meaning
}

\author{
Tami Yaguri \\ The Academic College of Society and the Arts, Netanya, Israel \\ Email: tami.yaguri@gmail.com
}

\begin{abstract}
Meaningful life is tightly connected with psychological well-being (Frankl, 2014; Stegera, Oishib \& Kashdanc, 2009). Meaningfulness is present in strong connections with self, others and the world (Debats, Drost \& Hansen, 1995). Formulating meaning in one's life is an art. The "art of meaning" is an approach of focusing and formulating meaning in dialogical exchange, with a semistructured interview, developed to draw out meaning in a person's life (Yaguri, 2018). Meaning appears at the overlap of self-identity and worldview. Through dialogue with an interviewee, a mutually satisfying formulation emerges. Once formulated, it contributes to clarity of thought, and sketches a line connecting fundamental life decisions.
\end{abstract}

Keywords: Meaning in life, purpose in life, happiness, pleasure, optimal experience, well-being, existential meaning, self-identity, worldview.

\section{Introduction}

This paper proposes replacing the quest for happiness with the art of formulating meaning. Everyone needs meaning in life, but not everyone makes a meaningful life for themselves (Frankl, 2014). Everyone wants their life to express their own choices, yet many perceive themselves as victims of circumstance. They find themselves caught between meaning and senselessness. Few will say wholeheartedly that they live the life they wish to live or the best version of their lives. The more meaning in life affirmed, the greater the well-being experienced at all life-stages (Stegera, Oishib \& Kashdanc, 2009: 48). The art of formulating meaning grapples with this meaning-deficit. It aims for straightforward assertions - this is my life; it is the most meaningful one I can live (Yaguri, 2018).

The pursuit of happiness has to make room for a pursuit of meaning. The self-identity of a meaningseeker and the power of her worldview provide stability of meaning through the passage of time. An approach to formulating such meaning, called "art of meaning," is characterized here (Yaguri, 2018). Through a semi-structured interview, the meaning of a person's life is drawn out. It appears at the overlap of self-identity and worldview. A positive value is mutually formulated to separate the essential from the inessential in a person's existence. Pursuing the "art of meaning" culminates in a mutually satisfying formulation, a short phrase that illuminates major life-decisions and preferences. Success contributes to clarity of thought, and sketches a line connecting fundamental life-decisions and values. I provide a sample interview to illustrate this process of articulating meaning.

\section{Happiness, Pleasure and Optimal Experience}

Psychiatrist Victor Frankl, the founder of logotherapy, predicted that the worst epidemic of the 21st century will be depression due to lack of meaning (2014). Indeed, it seems that the consumption-culture of affluent society and the vast use of antidepressants are attempts to fill a lack of meaning in life. A pursuit of "Science of Happiness" flourishing in academia and elsewhere, attests to a distressing existential vacuum. Frankl emphasized, however, that happiness is not the solution--it is part of the problem.

A Holocaust survivor, Frankl reveals his personal experience in a Camp: "We all said to each other in camp that there could be no earthly happiness which could compensate for all we had suffered. We were not hoping for happiness - it was not this hope that gave us courage and gave meaning to our suffering, our sacrifice and our dying." (Frankl, 2014: 86-87). 
Even as we continue to strive for happiness, depression will not disappear. The quest for happiness is deceptive. Like the horizon, happiness moves farther away from us as we work to reach it. It is not a goal that can be marked as the end-point of a straight path. It is a by-product of actions that give our lives meaning. While direct striving for meaning can produce happiness, a direct pursuit of happiness brings only depression (Frankl, 2014).

The mistaken idea that a person fulfills herself when she is happy, originates in the philosophy of Epicurus (341-270 BC). Epicurus believed that the purpose of human life is striving for pleasure and avoidance of pain. Sensual pleasures and the pleasures of the soul, define a happy life. Aristotle (384-322 BC) uses the Greek word "Eudaimonia" to cover happiness, well-being, and spiritual welfare. For him, happiness is attained through complete devotion to human reason. Our popular ideal does not aim at Aristotelian happiness, but at Epicurean happiness.

Science tells us that happiness can be achieved through stimulation of the brain's pleasure center. Lab rats attain happiness when electrodes are attached to the brain's pleasure centers. When a rat activates pleasurable stimulation it ceases to be interested in sex or food. It desires only to continue experiencing raw pleasure (Olds \& Milner, 1954: 419-427). Humans, too, can reach a happiness that bridges the way they are and the way they want to be. Alcohol, hallucinogenic drugs, and "settling for the way things are" work this way. But would we say these routes to happiness are routes to a meaningful life? Susan Wolf writes that "meaningfulness [is] an attribute lives can have that is not reducible to or subsumable under either happiness, as it is ordinarily understood, or morality." (2010: 3).

We can distinguish between a delightful happiness and the pleasures of satisfaction stemming from activities such as eating, drinking, buying, and so forth. Pleasures of satisfaction contribute to the quality of life (Yalom, 2000). The happiness achieved by lab rats does not create further happiness, new awareness, or enjoyment.

Like pleasure, enjoyment satisfies needs and passions in accordance with our expectations. But it continues beyond that. Enjoyment fulfills a sense of innovation, achievement, and contentment. Contentment is the outcome of meeting a challenge - in sports, in reading difficult material or engaging in deep conversation. Challenges that culminate in contentment are not necessarily pleasurable or delightful while they are taking place. Their gratification often comes afterwards. We change, become more complex and accomplished. This distinction between pleasure, delight, or happiness, and deep satisfaction, contentment, or enjoyment, shifts us away from making pleasure or happiness our central aim (Csíkszentmihályi, 2008: 45-48).

Some lives are fraught with painful struggle yet full of meaning. A meaningful life can lack pleasure or simple happiness. We can hope to attain both. If we must choose, however, it's better to choose satisfactions of meaning rather than transient pleasures or happiness. Pleasure may be transient but meaning can last till the end of one's life.

\section{Meaning: Past, Present and Future}

Those who have lost meaning seek to restore it. How is meaning lost? A person setting out to recover meaning might assume that it was there and then just disappeared, say, with a turn for the worse in her life. Suddenly things seem empty. Perhaps all she must do is look to the past to find it hiding. Searching meaning involves gazing forward and back from a present vantage point (Frankl, 1978: 105). However, it's impossible to gaze in both directions at once. Which way should we glance primarily to find meaning? Should we search in the life that we have already lived, in the life yet to be formed or in the present where action is required? (Sherover, 1975). We are asked about meaning in life every moment, and we have a duty to respond. Frankl says that our response must be "not in talk and meditation, but in right action and in right conduct. Life ultimately means taking the responsibility to find the right answer to its problems and to fulfill the tasks which it constantly sets for each individual." (Frankl, 2014: 72).

Meaning in life is an end in itself. Frankl identifies meaning in life with mental health. It provides justification for the life we have lived and affirms it (Frankl, 1988). It is not a condition for survival. Creatures that do not give meaning to their lives survive by biological instincts and mechanisms. But in humans there is another urge beyond striving for the future with goals tasks, plans and dreams: to live in recognition of the past. 
Meaning can be found in the everyday as well as in other-worldly spiritual experience. According to Frankl, hunger for meaning is present in everyone, even as its content varies from person to person, from day to day and from hour to hour (Frankl, 2014). What is important for our mundane existence is not the meaning of life in general, but the specific meaning of a specific human life at a given moment. Meaning is dynamic, anchored in the way each person responds to the world. It is based on realities of the past, Frankl holds, not on possibilities of the future. The great achievement of finding meaning in life, according to Frankl, lies in the ability of a person to survey his past and be optimistic about what has happened (Frankl, 1978).

There is a connection between the way a person tells the story of his life and the meaning of his life. A life story does not have to include the entire life of the narrator (Josselson, 2013; Lieblich, TuvalMashiach, Zilber, 1998). In fact, even one concrete example based on the narrator's facts of life can be a depository of life's meaning for that narrator.

In the "art of meaning" approach, a stable dimension of meaning in life - connecting past, present and future -is expressed in the relative stability of self-identity and of worldview (Yaguri, 2018). "Meaningfulness [is] found to be strongly associated with contact with self, others and the world, whereas meaninglessness [is] associated with a state of alienation from self, others and the world" (Debats, Drost \& Hansen, 1995: 359). A cohesive self-identity gives a unique character to a meaning that transcends the past to enter the present and even the future. In addition, a connection to a worldview - the way we observe the world around us - adds to stability of meaning in life. The selfidentity of a seeker and the power of her worldview provide stability of meaning through the passage of time.

\section{Method}

\subsection{Art of Meaning: Interview Structure}

The "art of meaning" is an approach whose aim is to help persons who are seeking to formulate the meaning in their lives. They may have confidence that their life has meaning but wonder how it can verbalized. The approach can help mental health professionals to identify a coherent and stable answer to the question of life's meaning for persons unsure how to express their sense of meaning. From a number of possible interpretations, the attentive dialogue-partner artfully selects, with the interviewee, an interpretation that offers the greatest positive value to the seeker. The semi-structured interview format includes four questions focused on a story segment provided by the interviewee.

1. What is the meaning of your life? If the interviewee hesitates or has difficulty, the interviewer can suggest an alternative wording: What is important to you? Upon a reply, the interviewer asks for a concrete example, a story segment or salient event that expresses these important things.

2. What is important in the story? The interviewer listens for the subjects or character traits that appear to be most important to the interviewee. Based on this intuitive mapping of importance, the interviewer reflects back to the speaker different possibilities that might be chosen as the most important thing in the story. The interviewee is asked which of these seems most salient.

3. Why is this important? Meaning in life expresses personal identity and also a broader worldview shared by others. This third question seeks to frame a worldview that captures the initial expression of things of personal importance provided by the interviewee. Worldview reflects widely shared values. Collecting corks or soap bubbles can be important to a person, but hardly rich enough to contain a worldview. Hobby is too personal to count as worldview. Helping others, in contrast, has an encompassing importance. This strand of the interview brings out how the things of importance chosen are widely valuable, not merely from the subjective point of view of the interviewee. What was initially presented as a private position is now seen as of general importance. If the meaning had been prefaced by the qualification, "in my opinion it is important," it can now carry the broader assurance, "it is important."

4. What value is expressed by that worldview? The goal is to present in a word or phrase a summary of the meaning first formulated as solely of personal importance and now as a broad culturally recognized value. This gives the meaning broad social and cultural justification. To move from an intuitive personal meaning to a broad cultural value is extracting a diamond from coal. The value 
should "ring true" for the interviewee. At this point a value rooted in personal experience is shown to have sweeping cultural significance deep enough to settle the quest for meaning in life.

I now present a detailed interview with the moves from seeking to finding and formulating a meaning in life.

\section{2 "Willpower to Stand Up for Myself"-An "Art of Meaning" Interview}

Here is an interview that follows the "art of meaning" structure I have described above. It takes steps from the first question and a story segment through the next three questions concluded in a formulation of meaning in life.

When Tali (a pseudonym) walks into a room, everything changes. Her body flows to the beat of flamenco, her warm gaze, her penetrating brown eyes that see everything, her black hair - these charge the surrounding space with energy about to burst into wild dance. She is a movement therapist. How could she not be? Her being is a combination of dancing and psychology, therapy and movement.

"What in life is meaningful for me?" She repeats the question pensively with a look that withdraws inwardly. "Above all, my family, my children. They are the reason I am here. Being a mother is my gift, the privilege of being self-fulfilled in a way that's complex and challenging. This fullness is more than hearing what $I$ want and thinking only in my way."

After a moment she adds, "Something else speaks to me that I have no control over. It's the desire to grow, to develop. I live with desires that coerce me. I live them outwardly."

"A story pops into mind!" Tali speaks with energy. I had asked her to illustrate that demand for growth and development she mentioned as necessary to meaning in her life. She said it coerced her and was not a matter of choice. "Before I went to the army service, my dream was to become an infantry instructor. It was the most challenging position for girls, like being a pilot today. My scores from the selection process were too low, so I battled to make them let me retake the exams. I did, and this time I passed. Two days after the course began, we were ordered to line up, and the names of the two girls with the lowest scores were called out and asked to leave. There were too many cadets in the course. One girl left the lines and got on the bus that passed through the military base once a day. I looked for Talia, who was also supposed to leave.

"In the shower, as the water flowed down on my head, I realized that $I$ was Talia. They had called out a name I never used. My first name from my identity card was 'Talia.' But I was 'Tali.' From that moment, I found the strength to pull off a move I will never forget. I refused to leave. I was transferred to the commander of the base, who was interviewing new officers that day. They let me wait for him for nine hours. I sat in a room with the secretaries, and heard the shouts from his room: who is this girl refusing to leave the base? Despite my deep fear, and maybe thanks to it, I insisted that I was a person, and that I deserved to be heard.

When he left the room, it was already night. The secretaries hinted with a wink that I should stand up. I asked him: are you the base commander? He asked: and you are? I answered: I'm the one who refuses to leave the course. He raised his voice: you are addressing me without your uniform, and without saluting. I immediately saluted. But it was with the wrong hand. He watched me as if I were an odd creature and said: I'm sorry, but I need to be at a meeting somewhere else.

I felt a rug had been pulled from under my feet. My dream had been shattered. That flamenco spirit spoke up from within. I looked him straight in the eye, stomped my feet, and said: "I'm a person and you will pay attention to me." He replied angrily: "I am the commander." I stomped my feet again and said: "I'll wait here a month and you'll pay attention." At this point, a crowd of curious people gathered. Who was this girl disputing the commander's authority. After a long gaze, he told me: "okay, go into the room, you have two minutes." The secretaries were ecstatic. My heart began pounding. I realized this was the moment. I had gone through so much for this.

He sat behind the long table that separated us: 'soldier, what is your name?' I wanted to talk, but no words came out. He asked me again, impatient. Inside, I was flooded with tears. He said angrily: 'this is a command; tell me your name.' And it flew out: 'my name is Tali! Do you hear? Tali!' He looked at me, and I looked at him, and I burst out sobbing. I felt as if I had been reborn at that moment. From then on, a connection was formed, a unique connection of listening and of professionalism between us. It was twenty-something years ago." 
The interviewer asked, "What's most significant in that story of you and the commander?" Tali dives in. "It is the place of birthing the self, the mental birth of my ability to seize a place in the world - from within me, and for me. And it's the power to cope with adversity. When everything is working against me, there is an inner place of power and of physical strength to stand up for myself: this is it, I am who I am; I am a person equal to others, my choices have a place in the world. Inner strength enabled that birth, and everything that happened afterward."

"You're talking about the strength to stand up for yourself, to want for yourself?"

"Yes. It is a strong place of black and white, in which I stubbornly persevere to the end."

The interviewer repeated Tali's words: "The strength to stand up for yourself, and to go with yourself, for yourself, all the way." Then the interviewer asked: "Where did you run into this type of strength in your life? Who is the source of inspiration? The model?"

"My father was a model of strength and willpower. I accepted his direction consciously. I adopted his strength in order to confront him, and mostly, in order to avoid the passive way of my mother. She doesn't take up any space in the world; she exists, but isn't present."

"That's a hard choice of words," the interviewer said.

"That's the way it is," she answered.

The interviewer asked her to give an example of her father's willpower, standing his ground.

"My father is the only cancer patient who is still alive after more than twenty-five years, against all the metastases and risks. At the age of seventy-five he still works like a twenty-five year old. Full of plans for the future, life-loving, scared to death of death. Life is everything for him. He is unwilling to give it up in any way. He is a sort of dinosaur. I love him, and I always have, but it's hard to live next to him. An actual pain. Nevertheless, I'm very attached to his vitality. He's grown wiser with the years, which helps my relationship with him a bit. But this is not why he survives cancer. He has found ways to live with the cancer like someone who lives with diabetes. He has the power to endure. He has already been through critical phases, through cycles of deterioration and recovery. When you look at him you don't see a sick man."

The interviewer, getting ready to conclude, suggests, "Tali, it seems to me that the value we are left with is the willpower to stand up for yourself. At first, you characterized the meaning of your life as children and family. But now it appears that the willpower to live your life and your choices takes precedence. It fuses together with the desire you spoke about - the desire to express who you are as you are."

Tali agreed, "My children are my most profound choice; they are my offspring. But, at the same time, they are on their own. My willpower to live life is expressed in my desire to have children. There's a connection that makes the two one desire."

\section{Discussion}

Tali's life story, like every life story, is composed of numerous varied events and situations, details and facts that are collected and accumulated over a lifetime (McAdams, Josselson, Lieblich, 2006). The process that takes place in an "art of meaning" interview is intended to extract a main essence from the many details (Yaguri, 2018). The extracted essence is a leitmotif for the narrative. Through the process of the semi-structured interview, Tali's complex story is transformed into a concise formulation of an essence in her life. The "art of meaning" sees meaning as an essence, which is also the life story's essence.

For Tali it was an attempt to formulate the main value in her life. If it were not for the process that she went through, the phrase "willpower to stand up for myself" would have sounded too bombastic for her. It would not have come up as a main motive and essence of her life. After having laid the groundwork through her story of confronting her military commander the phrase "willpower to stand up for myself" was no longer bombastic but a simple articulation of meaning. Its concise focus enabled her to look at her life under a new light. The process gave her confidence to affirm the value found. In retrospect, she realized that this meaning inspired her all along. She had a new appreciation of who she was and her role in the world.

The meaning revealed expands Tali's perception of herself and her life. Willpower to stand up for herself is the energy that shapes her world and daily life (Yaguri, 2014). Pursuing the questions that guide the "art of meaning" enable her to see that her willpower in striving to accomplish her goals, her 
insistence to be heard and her courage to stand up for her will, are the heart of the matter. Her family and children - the initial meaning that she posits - remain central. But now they are perceived by as the outcome of her willpower to stand up for herself. The two are like macro and micro, two levels of the same thing, her will.

The wording that emerged through the interview made Tali's meaning more universal (Wolf, 2010). Suddenly she realizes that her meaning is similar to her father's. It was a surprise to her. She perceived his way as different from her own. But she comes to see that she shares a path of meaning with him. That discovery expands the circle of partners and friends who share her meaning. At the same time her sense of her own meaning becomes more accurate.

Like Tali, many may have a general idea of the meaning in their lives but lack a concise formulation. Clarity of formulation translates into quality of life. When a person can formulate her meaning in a few words she can look through it to focus herself and her life. Meaning becomes glasses for examining her past and the way to her future (van Deurzen, 1997). Formulated meaning assists self-realization. It can serve as a north-star that guides decision-making.

Formulating meaning in life contributes to well-being. It punctuates self-understanding and becomes its framework. On a daily basis and in times of difficulty, meaning in life serves as a navigational aid. Life-events receive focus and justification. One has a reminder of the truly important essence of one's life.

\section{References}

1. Csíkszentmihályi, M. (2008). Flow: The Psychology of Optimal Experience. New York: Harper Perennial Modern Classics.

2. Debats, D. L., Drost, J., Hansen, P. (1995). "Experiences of meaning in life: A combined qualitative and quantitative approach." British Journal of Psychology. 86, 359-375.

3. van Deurzen, E. (1997). Everyday Mysteries: Existential Dimensions of Psychotherapy. New York: Routledge.

4. Frankl, V. E. (2014). Man's Search for Meaning. Boston: Beacon Press.

5. Frankl, V. E. (1988). The Will to Meaning: Foundations and Applications of Logothearpy. New York: Penguin Books.

6. Frankl, V. E. (1978). The Unheard Cry for Meaning: Psychotherapy\&Humanism. New York: Simon\&Schuster Inc.

7. Josselson, R. (2013) Interviewing for Qualitative Inquiry: A Relational Approach. New York: The Guilford Press.

8. Lieblich, A., Tuval-Mashiach, R., Zilber, T. (1998). Narrative research: reading, analysis and interpretation. Thousand Oaks, CA: Sage.

9. McAdams, D. P., Josselson, R., Lieblich, A. (edts.) (2006). Identity And Story: Creating Self in Narrative. Washington, DC: American Psychological Association.

10. Olds, J. \& Milner, P. (1954). Positive Reinforcement Produced by Electrical Stimulation of Septal Electrical Stimulation of Septal Area and Other Regions of Rat Brain. Journal of Comparative and Physiological Psychology 47 (6): 419-427.

11. Sherover, C. M. (1975). The Human Experience of Time. New York: New York University Press.

12. Stegera, M. F., Oishib, S., Kashdanc, T. B. (2009). "Meaning in life across the life span: Levels and correlates of meaning in life from emerging adulthood to older adulthood." The Journal of Positive Psychology Vol. 4, No. 1, $43-52$.

13. Wolf, S. (2010). Meaning in Life and Why It Matters. Princeton and Oxford: Princeton University Press.

14. Yaguri, T. (2018). Unraveling Life's Riddle. Newcastle upon Tyne: Cambridge Scholars Publishing.

15. Yaguri (Aylat-Yaguri), T. (2014). Kierkegaardian Selves: The Will Transformed. SEA: The Society for Existential Analysis. 25.1: 118-129.

16. Yalom. I. D. (2000). Momma and the Meaning of Life. New York: Harper-Perennial. 